\section{Subjecting Radiologic Imaging to the Linear No-Threshold Hypothesis: A Non Sequitur!}

TO THE EDITOR: Siegel et al. have again forced the scientific community to rethink the linear no-threshold (LNT) hypothesis. In their recent article in The Journal of Nuclear Medicine (1), these authors reviewed the data on low-level radiation and documented the absence of carcinogenesis in humans below acute or subacute exposures of $100 \mathrm{mGy}$ or less. An even more comprehensive data analysis by these authors, when space for publication was not limited, appeared in Biological Theory in 2016 and included 105 references (2).

It is true that for ethical reasons, we cannot prove Siegel et al. correct in a controlled prospective study. However, these data are certainly not the only kind we accept scientifically. There are also ample epidemiologic and in vitro data to support the contention of Siegel et al. (1-4). And where can be found the excess cancers that the LNT hypothesis says should exist?

I would ask the readers of $J N M$ to review the first two articles cited above to understand that the LNT hypothesis carries its own potential for damage-damage to populations, from needless evacuations such as at Fukushima, and damage to individuals, from poor-quality studies because of inadequate radiation and from patient avoidance of studies because of radiophobia. It is not impossible to study the "risk" of medical radiation versus the risk of not performing an imaging study.

I would further request that, for any article attempting to estimate the number of cancers allegedly caused, or averted, by low-level radiation from any source, including radiation dose alterations due to changes in nuclear medicine/radiologic technique, the $J N M$ insert verbiage indicating that these estimates are based on an unproven hypothesis, LNT, for which no credible data have survived scientific scrutiny. Could not such verbiage - this proposed "JNM approach"be publicized and shared with all journals dealing with radiation and carcinogenesis? Such an approach to radiation carcinogenesis data in humans would be a great boon both to the public we serve and to the many scientists and physicians who may not have the time, or the background, to scrutinize these data as intensely as have Siegel et al.

\section{REFERENCES}

1. Siegel JA, Pennington CW, Sacks B. Subjecting radiologic imaging to the linear no-threshold hypothesis: a non sequitur of non-trivial proportion. J Nucl Med. 2017;58:1-6.

2. Sacks B, Meyerson G, Siegel JA. Epidemiology without biology: false paradigms, unfounded assumptions, and specious statistics in radiation science. Biol Theory. 2016;11:69-101.

3. Kant K. Radiation hormesis in humans exposed to low level ionizing radiation. Asian J Chem. 2009;21(suppl):S188-S194.

4. Feinendegen LE. Evidence for beneficial low level radiation effects and radiation hormesis. Br J Radiol. 2005;78:3-7.

Edward B. Silberstein University of Cincinnati Medical Center 234 Goodman St., Room G026, Mont Reid Pavilion

Cincinnati, $\mathrm{OH} 45219$

E-mail: silbereb@uc.edu

Published online Mar. 16, 2017. DOI: 10.2967/jnumed.117.192690 